\title{
Fitossociologia e fatores ecológicos condicionantes da vegetação em uma floresta estacional na região central do Rio Grande do Sul, Brasil
}

\author{
Rafael Marian Callegaro', Maristela Machado Araujo', Solon Jonas Longhi ${ }^{2,3}$, \\ Camila Andrzejewski ${ }^{2}$, Felipe Turchetto² \& Daniele Rodrigues Gomes ${ }^{2}$
}

\author{
' Universidade Federal do Espírito Santo, Departamento de Ciências Florestais e da Madeira, Av. Governador Lindenberg, n. 316 , \\ 29550-000, Jerônimo Monteiro, ES, Brasil. rafaelm.callegaro@gmail.com \\ ${ }^{2}$ Universidade Federal de Santa Maria, Departamento de Ciências Florestais. Av. Roraima, s/n, Camobi, 97105-900, Santa Maria, RS, Brasil. \\ araujo.maristela@gmail.com, longhi.solon@gmail.com, camiandrzejewski@gmail.com, turchetto.felipe@gmail.com, eng.danielegomes@gmail.com \\ ${ }^{3}$ Universidade Tecnológica Federal do Paraná, Programa de Pós-Graduação em Agroecossistemas, \\ Estrada para Boa Esperança, km 04, 85660-000, Dois Vizinhos, PR, Brasil. solonj.@utfpr.edu.br
}

Recebido em 13.VII.2015

Aceito em 20.IV.2017

DOI: $10.21826 / 2446-8231201772104$

\begin{abstract}
RESUMO - Compreender a fitossociologia e fatores ecológicos condicionantes pode subsidiar intervenções em florestas. Nesse contexto, objetivouse analisar os componentes arbóreo e regenerante e a influência das variáveis ambientais na distribuição de espécies, em uma Floresta Estacional na região central do Rio Grande do Sul. O estrato arbóreo foi amostrado em 33 parcelas instaladas sistematicamente, sendo em cada parcela instaladas subunidades para amostrar a regeneração natural. As principais espécies no componente arbóreo foram Trichilia clausseni C.DC. e Nectandra megapotamica (Spreng.) Mez e na regeneração natural foram Trichilia elegans A. Juss. e Cupania vernalis Cambess. Relevo, solo e dossel condicionaram espécies do estrato arbóreo e regeneração natural. O estádio regenerante das espécies foi condicionado por variáveis distintas das relacionadas ao estádio adulto. Contudo, ocorreram casos em que apenas uma variável, por exemplo, a relação entre o teor de matéria orgânica no solo e Trichilia elegans, influenciou tanto o estádio adulto quanto o regenerante.
\end{abstract}

Palavras-chave: conservação florestal, ecologia, relação ambiente-vegetação

\begin{abstract}
Phytosociology and ecological factors on vegetation in a seasonal forest in the central area of Rio Grande do Sul, Brazil. Understanding the phytosociology and conditioning ecological factors of the vegetation can subsidize interventions in forests.. We analyzed the arboreal stratum and natural regeneration, as well as the influence of environmental variables on species distribution in a seasonal forest in central Rio Grande do Sul, Brazil. Thirty-three plots were systematically installed for the arboreal stratum sampling. In each plot, the natural regeneration Class I and Class II were measured. The main species were Trichilia elegans and Cupania vernalis in natural regeneration and Trichilia clausseni and Nectandra megapotamica in arboreal stratum. Relief, soil, and canopy influenced the arboreal stratum and natural regeneration of species. In general, the regenerating stage of the species was conditioned by distinct variables from those related to the adult stage. However, there were cases where only one variable influenced both the adult and the regenerating stages, such as the relationship between soil organic matter content and Trichilia elegans.
\end{abstract}

Keywords: ecology, forest conservation, relations environment-vegetation

\section{INTRODUÇÃO}

No Rio Grande do Sul, as florestas estão distribuídas por diferentes paisagens sendo, na região central do Estado, encontradas principalmente em áreas declivosas. As relações naturais entre o ambiente e a vegetação, e os distúrbios de origem humana influenciam a florística e a estrutura das florestas, como no Parque Estadual Quarta Colônia (PEQC), uma Unidade de Conservação. Sassen \& Sheil (2013) enfatizaram a importância de compreender os impactos humanos sobre a vegetação para o gerenciamento de florestas destinadas à conservação da biodiversidade.

Interferências antrópicas como a derrubada de florestas para o cultivo, o estabelecimento de pastagens ou a extração de madeira causam impactos de maneira intensiva e extensiva (Chazdon et al. 2007, Chazdon 2012). Apesar de não promoverem a substituição da cobertura florestal, alguns impactos antrópicos, como o corte seletivo de madeira para serraria ou lenha e o pastoreio no interior da floresta, podem ser tão profundos ao ponto de causarem alterações florísticas e estruturais persistentes por décadas (Liebsch et al. 2016). Os diferentes usos anteriores da floresta desempenham, segundo Fortuny et al. (2017), um papel importante na formação da atual estrutura e diversidade da floresta restabelecida. Nesse contexto, as trajetórias sucessionais variam amplamente conforme a intensidade dos distúrbios, a proximidade de uma floresta primária e a presença da fauna (Chazdon et al. 2007). Assim sendo, a evolução sucessional de uma área de floresta é determinada pela capacidade de regeneração natural do local, que por sua vez é influenciada por aspectos como a dispersão de diásporos e as interações biológicas, que venham a ocorrer ao longo da sucessão.

As florestas com histórico de perturbações tendem a ser constituídas por comunidades em diferentes estádios sucessionais, com estrutura e florística distintas. Esta 
heterogeneidade resulta parcialmente, segundo Chai \& Tanner (2011), no aparecimento de diferentes espécies em momentos distintos durante a sucessão. Portanto, a presença de espécies com populações arbóreas mais densas indica quais espécies chegaram à área e obtiveram sucesso no respectivo desenvolvimento.

Considerando a fisionomia arbórea de áreas antropizadas em relação a esperada em ambientes cobertos por florestas, torna-se importante entender os mecanismos de transformações da composição florística e da estrutura ocorrentes na sucessão secundária, uma vez que a regeneração natural impulsiona a restauração das florestas após distúrbios naturais ou antrópicos (Marchesini et al. 2009, Silva et al. 2010). Acrescenta-se que diferenciar a estrutura do componente arbóreo e da regeneração natural pode evidenciar quais comunidades florestais se apresentam em estádios sucessionais distintos e fornecer indícios sobre a dinâmica de populações e de comunidades.

As Florestas Estacionais na região central do Rio Grande do Sul têm sido abordadas em pesquisas que consideraram comunidades florestais sobre relevo heterogêneo ou ambientes ciliares (Giehl et al. 2007, Scipioni et al. 2010). No entanto, poucos trabalhos trataram conjuntamente a regeneração natural e o estrato arbóreo, relacionando-os com o ambiente (Marcuzzo et al. 2013). Pesquisas sobre as relações entre variáveis ambientais e as espécies no componente arbóreo e no regenerante auxiliam a entender a formação de comunidades florestais. Nesse contexto, o presente estudo teve como objetivo descrever a fitossociologia do componente arbóreo e da regeneração natural, bem como analisar a influência de variáveis ambientais sobre a distribuição de espécies, em uma Floresta Estacional Decidual, localizada na região central do Rio Grande do Sul, Brasil. Buscou-se responder aos questionamentos: i) as espécies melhor estabelecidas no componente arbóreo apresentaram o mesmo padrão na regeneração natural? ii) quais variáveis ambientais foram mais relacionadas com a distribuição das espécies na floresta? iii) espécies em estádio de regeneração e no componente arbóreo foram relacionadas com diferentes variáveis ambientais?

\section{MATERIAL E MÉTODOS}

A área da pesquisa encontra-se em uma Unidade de Conservação de Proteção Integral, o Parque Estadual Quarta Colônia (PEQC), localizada entre as latitudes $29^{\circ} 27^{\prime} 20,2^{\prime \prime}$ S e $29^{\circ} 27^{\prime} 54,3^{\prime \prime}$ S e as longitudes $53^{\circ} 16^{\prime} 19,66^{\prime \prime}$ O e $53^{\circ} 16^{\prime} 55,3^{\prime \prime} \mathrm{O}$, no município de Agudo, RS, Brasil (Fig. 1A).

O relevo na área varia de suave (declividade menor que $8 \%$ ) a escarpado (declividade maior que $75 \%$ ). Na área predominam os Neossolos Litólicos (Pedron \& Dalmolin 2011), muitas vezes associados à pedregosidade superficial do solo. A altitude média na área de amostragem é 218 $\mathrm{m}$, com mínima de $85 \mathrm{~m}$ e máxima de $372 \mathrm{~m}$ de altitude.

O clima da região, de acordo com a classificação de Köppen, é do tipo Cfa (subtropical), com precipitação pluviométrica e temperatura média anuais próximos de $1.800 \mathrm{~mm}$ e $20^{\circ} \mathrm{C}$, respectivamente (Wrege et al. 2011, Alvares et al. 2013).

A vegetação pertence à região fitoecológica Floresta Estacional Decidual (IBGE 2012), apresentando diferentes estádios de sucessão, com predomínio do estádio médio e avançado de regeneração natural, com pequenas áreas em estádio inicial (Marcuzzo et al. 2013). O histórico da área de abrangência do PEQC explica o mosaico sucessional presente nesse perímetro, anteriormente constituído por propriedades rurais. Essas propriedades eram ocupadas para cultivos agrícolas adjacentes ao remanescente florestal. Evidências pontuais da intervenção antrópica no PEQC incluem estradas abandonadas, comunidades arbóreas com pouca amplitude de variação do diâmetro e clareiras originadas do abandono de cultivos agrícolas, onde ocorre o domínio de gramíneas, como por exemplo Cortaderia spp. Relatos de moradores presentes na faixa
(A)

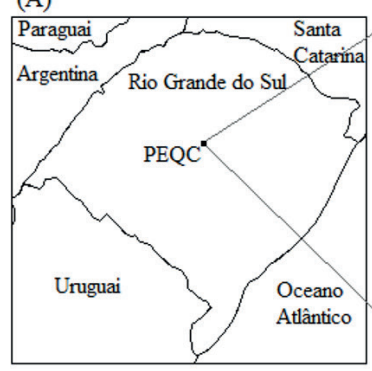

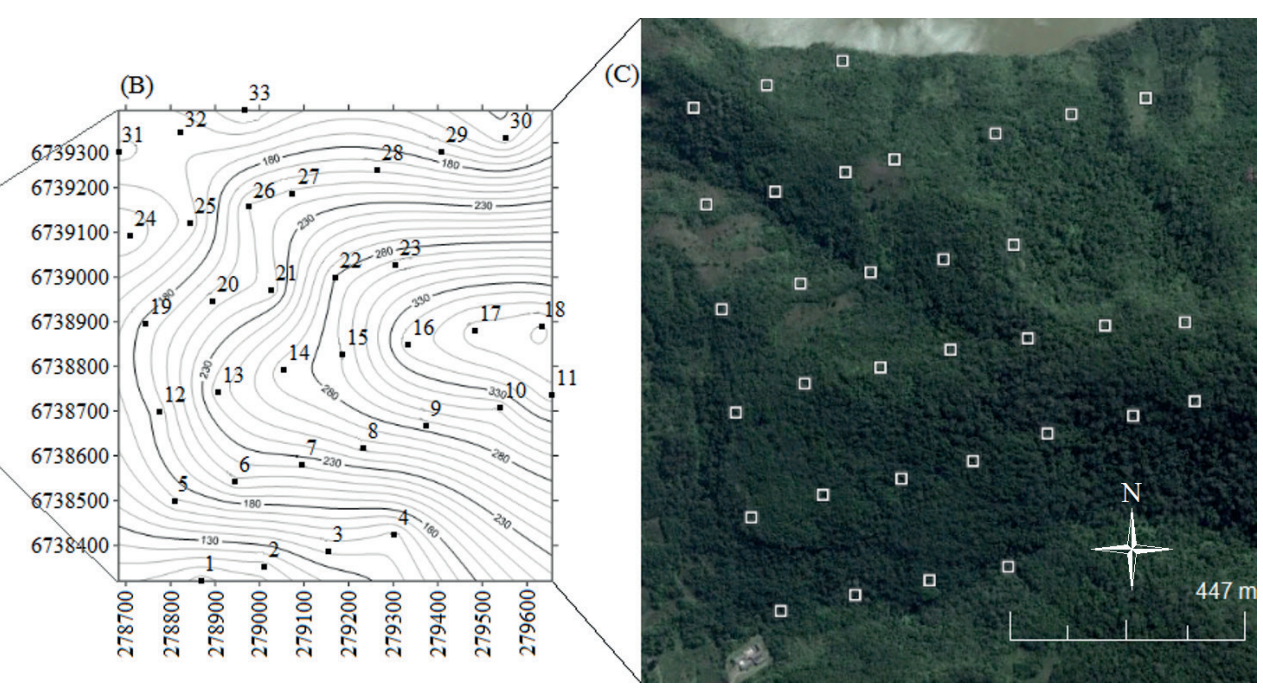

Figs. 1. A-C. A. Localização do Parque Estadual Quarta Colônia na região central do Rio Grande do Sul, Brasil; B. Disposição e orientação das 33 parcelas e isolinhas de altitude; C. Imagem de satélite da área de estudo. 
de amortecimento do PEQC indicam também a extração seletiva de árvores para obtenção de lenha e de madeira para serraria, no período anterior à demarcação do PEQC. Esta Unidade de Conservação foi criada pelo Decreto Estadual n. 44.186, de 19 de dezembro de 2005, como medida compensatória do licenciamento ambiental da Usina Hidrelétrica Dona Francisca, no rio Jacuí (Rio Grande do Sul 2005), englobando o território na margem sul e leste do reservatório.

Para a amostragem foram distribuídas sistematicamente 33 parcelas, com dimensões de $20 \mathrm{~m}$ x $20 \mathrm{~m}$ (1,32 ha de superfície amostral), em seis faixas paralelas mantendo-se a distância de $200 \mathrm{~m}$ entre as faixas e $130 \mathrm{~m}$ entre o fim de uma parcela e o início de outra parcela em cada faixa (Figs. 1B, C). Os indivíduos de espécies arbustivas, arbóreas e arvoretas com diâmetro à altura do peito $(\mathrm{DAP}) \geq 5,0 \mathrm{~cm}$ foram incluídos como pertencentes ao componente arbóreo. A coleta de dados do componente arbóreo foi realizada entre os meses de fevereiro e dezembro de 2013.

As subunidades para a amostragem da regeneração (componente arbóreo regenerante) foram instaladas dentro de cada parcela de $20 \mathrm{~m} \times 20 \mathrm{~m}$. Foram estabelecidas duas classes de regeneração natural: Classe I - indivíduos com $1,0 \leq$ DAP (medido a $1,30 \mathrm{~m}$ de altura do solo) $<5,0 \mathrm{~cm}$, e Classe II - indivíduos com altura $(\mathrm{H}) \geq 20 \mathrm{~cm}$ e DAP $<1,0 \mathrm{~cm}$. A Classe I foi amostrada em seções de $4 \mathrm{~m} \mathrm{x}$ $10 \mathrm{~m}$ e a Classe II amostrada em seções de $2,5 \mathrm{~m} \mathrm{x} 4 \mathrm{~m}$ (Fig. 2). A regeneração natural foi amostrada na primeira quinzena do mês de março de 2014. De cada indivíduo do componente arbóreo foi medida a circunferência à altura do peito (CAP, circunferência obtida a $1,30 \mathrm{~m}$ de altura do solo) e a altura total. Para as duas classes de regeneração natural foram mensurados a altura total dos indivíduos e para Classe I, da regeneração, também foi medida a CAP. Os valores medidos de CAP foram posteriormente transformados em DAP.

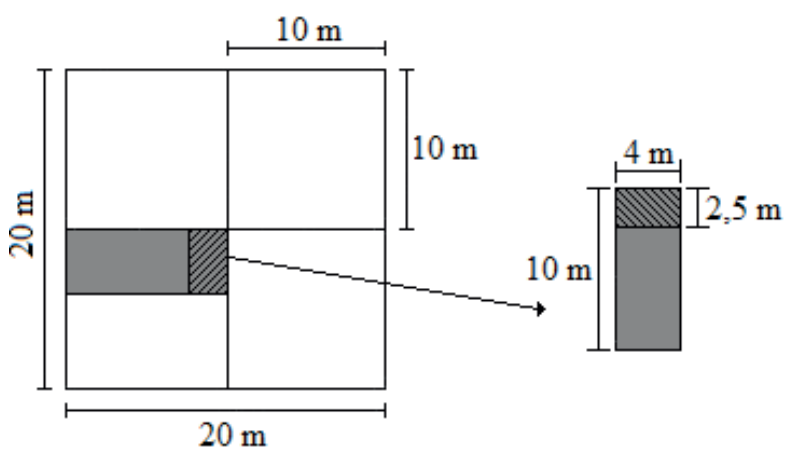

\section{Componente arbóreo $\square$ Classe I Classe II}

Fig. 2. Esquema gráfico das parcelas utilizadas para amostragem do componente arbóreo e regenerante Classe $\mathrm{I}=1,0 \leq \mathrm{DAP}$ (medido a $1,30 \mathrm{~m}$ de altura do solo) $<5,0 \mathrm{~cm}$ e Classe II $=\mathrm{DAP}<1,0 \mathrm{~cm}$ e altura $\geq 20 \mathrm{~cm}$, na Floresta Estacional da região central do Rio Grande do Sul.
O material vegetativo dos indivíduos não identificados in loco foi coletado para posterior identificação com auxílio de bibliografias, por comparação, com materiais identificados no acervo do Herbário do Departamento de Ciências Florestais da Universidade Federal de Santa Maria e por especialistas. As espécies foram classificadas dentro das famílias reconhecidas pelo sistema Angiosperm Phylogeny Group IV (Byng et al. 2016) e a confirmação da nomenclatura científica foi baseada na Lista de Espécies da Flora do Brasil (Forzza et al. 2015). Quanto ao hábito, as espécies foram classificadas, conforme Brack et al. (1998) e Marchiori (2013), em arbusto, arvoreta e árvore.

As variáveis ambientais obtidas incluíram características topográficas (declividade e exposição do relevo), abertura do dossel, características edáficas e espessura da serapilheira acumulada. A declividade, obtida em graus, foi medida com clinômetro digital. A exposição do relevo foi medida com uma bússola, em graus, em relação ao norte magnético. A localização meridional da região no Hemisfério Sul, faz com que as encostas voltadas ao norte recebem maior luminosidade (Oliveira et al. 1995). Considerando-se esse aspecto, a exposição em graus foi medida de $0^{\circ}$ a $180^{\circ} \mathrm{em}$ direção ao norte. Posteriormente, os graus foram transformados em radianos para compor a matriz de dados.

A abertura do dossel foi medida com um densiômetro esférico convexo, no centro da parcela a $1 \mathrm{~m}$ do solo (Scolari et al. 2010). Incluiu-se como variável do dossel, $\mathrm{a}$ área basal do estrato arbóreo em cada parcela.

Para análise química do solo, foram coletadas três amostras simples na profundidade de $0-20 \mathrm{~cm}$ em cada parcela de $20 \mathrm{~m} \times 20 \mathrm{~m}$, as quais constituíram as amostras compostas, que foram enviadas ao Laboratório de Análise de Solos da Universidade Federal de Santa Maria (UFSM) e analisadas conforme Tedesco et al. (1995). Entre os parâmetros determinados encontram-se: $\mathrm{pH}$ em água, $\mathrm{Ca}$ (cálcio), $\mathrm{Mg}$ (magnésio), $\mathrm{H}+\mathrm{Al}$ (acidez potencial), CTC efetiva (capacidade de troca de cátions), saturação de bases, MO (\% de matéria orgânica), S (enxofre), P-Mehlich (fósforo), $\mathrm{Cu}$ (cobre), $\mathrm{Zn}$ (zinco), $\mathrm{B}$ (boro), $\mathrm{K}$ (potássio) e relações molares $\left[\mathrm{Ca} / \mathrm{Mg},(\mathrm{Ca} / \mathrm{Mg}) / \mathrm{K} \mathrm{e} \mathrm{K} /(\mathrm{Ca} / \mathrm{Mg})^{1 / 2}\right]$. A granulometria da fração fina ( $\%$ areia grossa, $\%$ areia fina, $\%$ silte, \% argila) foi analisada no Laboratório de Física do Solo pelo método da pipeta, conforme os procedimentos descritos pela Embrapa-Cnps (1997).

A profundidade do solo foi medida com uma haste de metal de $13 \mathrm{~mm}$ de espessura e $1,50 \mathrm{~m}$ de comprimento. A haste foi pressionada até que atingisse a rocha, em que $o$ valor da profundidade foi obtido pela diferença entre o comprimento da haste e o comprimento da haste que ficou sob o solo. Foram obtidas três medidas em cada parcela de $20 \mathrm{~m}$ x $20 \mathrm{~m}$, sendo distribuídas aleatoriamente, as quais forneceram a profundidade média do solo.

A pedregosidade superficial foi avaliada visualmente conforme as classes descritas por Santos et al. (2013), em relação à presença superficial de calhaus $(2 \mathrm{a} 20 \mathrm{~cm}$ ) e/ou matacões (20 a $100 \mathrm{~cm}$ ). A pedregosidade foi expressa como variável ordinal, atribuindo peso maior para as classes com 
maior grau de pedregosidade, com as seguintes classes: 1 - não pedregosa; 2 - ligeiramente pedregosa (ocupa menos de $1 \%$ da superfície); 3 - moderadamente pedregosa (1 a $3 \%$ ); 4 - pedregosa (3 a 15\%); 5 - muito pedregosa (15 a $50 \%) ; 6$ - extremamente pedregosa (50 a 90\%); e 7 - terreno pedregoso (mais de 90\%).

A espessura da serapilheira acumulada foi medida com trena metálica, resultado da média aritmética de três pontos de medições, realizadas aleatoriamente nas parcelas da regeneração natural.

Foram calculados os parâmetros da estrutura horizontal (densidade, frequência, dominância e valor de importância) para o componente arbóreo (Souza \& Soares 2013) e para a regeneração natural foi calculada a densidade, frequência, categoria de tamanho e regeneração natural relativa (RNR, Finol 1971). A RNR (\%) foi obtida pela média aritmética dos valores relativos de abundância, frequência e categoria de tamanho (CT). Para o cálculo da CT foram estabelecidas inicialmente as classes de tamanhos de altura, baseadas em Sccoti (2012): Classe I: $20 \leq$ altura (h) $<50 \mathrm{~cm}$; Classe II: $50 \leq \mathrm{h}<100 \mathrm{~cm}$; Classe III: $100 \leq \mathrm{h}<150 \mathrm{~cm}$; Classe IV: $150 \leq \mathrm{h}<200 \mathrm{~cm}$; Classe V: $\mathrm{h} \geq 200 \mathrm{~cm}$ e DAP $<5$ $\mathrm{cm}$. Conforme Souza \& Soares (2013), a CT absoluta por espécie é obtida pela soma das multiplicações do número de indivíduos de cada espécie, em cada classe, pelo peso de cada classe de regeneração.

A CCA foi utilizada para correlacionar a distribuição das espécies do estrato arbóreo e da regeneração natural com o gradiente ambiental (Felfili et al. 2011). Para isso, foram elaboradas duas matrizes de dados: matriz de espécies e matriz de variáveis ambientais. A matriz de dados das espécies foi constituída pela abundância das espécies que apresentaram 10 ou mais indivíduos na amostra total. Os valores da abundância das espécies foram transformados pela expressão $\log _{10}(\mathrm{a}+1)$, para compensar desvios causados por valores elevados. Inicialmente, a matriz de variáveis ambientais foi composta por todas as variáveis mensuradas (Oliveira Filho et al. 2004). Foram excluídas algumas variáveis altamente correlacionadas $(\mathrm{r}>0,9)$, uma vez que a autocorrelação espacial dessas variáveis evidenciaria um efeito similar sobre a distribuição das espécies. Também foram removidas as variáveis fracamente correlacionadas $(\mathrm{r}<0,4)$ com os dois primeiros eixos da ordenação. Outro procedimento adotado foi retirar da análise final as variáveis que apresentaram vetores visivelmente próximos no mapa bi-dimensional preliminar, mantendo-se na análise a variável com maior correlação com os eixos de ordenação. Após os procedimentos preliminares, a CCA do componente arbóreo foi realizada com 33 parcelas, 39 espécies e cinco variáveis ambientais. A CCA da regeneração natural da Classe I foi realizada com 30 parcelas, nove espécies e quatro variáveis ambientais e da Classe II com 32 parcelas, 16 espécies e cinco variáveis ambientais. Algumas parcelas foram excluídas por não possuírem indivíduos das espécies analisadas.

A estrutura da regeneração natural e do estrato arbóreo e a análise de correspondência canônica foram processados, respectivamente, nos programas Mata Nativa 2 e $P C-O R D$ for Windows, versão 4.4 .

\section{RESULTADOS E DISCUSSÃO}

Foram amostrados 2.026 indivíduos no componente arbóreo, pertencentes a 76 espécies e 30 famílias botânicas, e 1.157 indivíduos na regeneração natural, distribuídos em 83 espécies e 35 famílias (Classe I: 51 espécies e 26 famílias; Classe II: 70 espécies e 32 famílias). Considerando o estrato arbóreo e a regeneração foram amostradas 99 espécies, sendo duas exóticas. Os valores de riqueza podem ser considerados elevados em comparação a outros remanescentes de Floresta Estacional Decidual (FED) (Santos et al. 2012, Lucheta et al. 2015), nos estádios adulto e regenerante. A elevada riqueza de espécies arbóreas na FED foi um aspecto evidenciado pela pesquisa de Schorn et al. (2014), ao analisar remanescentes desta tipologia no Estado de Santa Catarina. Contudo, deve-se considerar que a riqueza de espécies e a estrutura de comunidades florestais apresentam singularidades, devido à influência de fatores como o histórico de uso, condições edáficas e topográficas, entre outros (Scipioni et al. 2009). Nesse contexto, Chazdon et al. (2007) concluíram que a composição de espécies em comunidades florestais jovens é o reflexo de padrões locais de colonização das espécies e dos efeitos da vegetação remanescente. Outro fator relacionado à riqueza de espécies em florestas são os distúrbios causados pela queda de árvores (Baker et al. 2016). Assim sendo, os diferentes estádios sucessionais observados no PEQC estão associados à variação espacial dos fatores ambientais e pequenas clareiras, que possivelmente determinaram a alta riqueza de espécies, por proporcionarem maior heterogeneidade de nichos ecológicos para colonização de espécies.

No trecho florestal estudado, as espécies Trichilia clausseni (Valor de Importância Relativo, VIR=7,5\%), Nectandra megapotamica (7,1\%), Allophylus edulis (A.St.-Hil., Cambess. \& A. Juss.) Radlk. (5,9\%), Cupania vernalis (4,6\%), Sebastiania brasiliensis Spreng. (3,8\%), Parapiptadenia rigida (Benth.) Brenan (3,7\%) e Cordia americana (L.) Gottschling \& J.S.Mill. (3,4\%) tiveram os maiores VIR do estrato arbóreo (Tab. 1). Dessas espécies, A. edulis, C. americana, C. vernalis, N. megapotamica, $P$. rigida e $T$. clausseni estiveram entre as 10 principais espécies do estrato arbóreo, em outras Florestas Estacionais no Sul e no estado de São Paulo (Sühs \& Budke 2011, Scipioni et al. 2012, Schneider \& Rocha 2014, Jorge et al. 2015). As variáveis pedológicas e geomorfológicas associadas a outras variáveis, como luz e temperatura, afetam os aspectos florísticos bem como a autoecologia das espécies, as quais são importantes na determinação da distribuição destas em uma comunidade (Ferreira Júnior et al.2012). Por conseguinte, a densidade e a dominância de espécies no componente arbóreo também são influenciadas pelos aspectos supracitados.

No estrato arbóreo, algumas espécies como Trichilia clausseni (174,2 indivíduos/ha), Allophylus edulis (106,1), 
Tabela 1. Parâmetros fitossociológicos e hábito das principais espécies amostradas na regeneração natural e no sub-bosque/dossel em uma Floresta Estacional na região central do Rio Grande do Sul. $\mathrm{H}=$ hábito ( $\mathrm{a}=$ árvore; av = arvoreta; ar = arbusto); DA = densidade absoluta; CII: regeneração natural com altura $\geq 20 \mathrm{~cm}$ e DAP $<1 \mathrm{~cm} ; \mathrm{CI}=$ regeneração natural com $1 \leq \mathrm{DAP}<5 \mathrm{~cm} ; \mathrm{RNR}=$ regeneração natural relativa; DoA $=$ dominância absoluta; VIR = valor de importância relativo; ${ }^{\mathrm{a}}=$ entre as 20 espécies com maior RNR ou VIR.

\begin{tabular}{|c|c|c|c|c|c|c|c|}
\hline \multirow{3}{*}{ Espécies } & \multirow{3}{*}{$\mathrm{H}$} & \multicolumn{3}{|c|}{ Regeneração natural } & \multicolumn{3}{|c|}{ Estrato arbóreo } \\
\hline & & \multicolumn{2}{|c|}{ DA (ind.ha-1) } & \multirow{2}{*}{$\begin{array}{l}\text { RNR } \\
(\%)\end{array}$} & \multirow{2}{*}{$\begin{array}{c}\text { DA } \\
\text { (ind.ha-1) }\end{array}$} & \multirow{2}{*}{$\begin{array}{c}\text { DoA } \\
(\mathrm{m} 2 . \text { ha-1) }\end{array}$} & \multirow{2}{*}{$\begin{array}{l}\text { VIR } \\
(\%)\end{array}$} \\
\hline & & C II & $\mathrm{C}$ I & & & & \\
\hline Actinostemon concolor (Spreng.) Müll.Arg. (Acon) & $\mathrm{a}$ & 2424 & 371 & $8,7 \mathrm{a}$ & 62,9 & 0,30 & $2,1^{\mathrm{a}}$ \\
\hline Allophylus edulis (A.St.-Hil., Cambess. \& A. Juss.) Radlk. (Aedu) & $\mathrm{a}$ & 364 & 53 & $2,0 \mathrm{a}$ & 106,1 & 1,84 & $5,9^{\mathrm{a}}$ \\
\hline A. guaraniticus (A. St.-Hil.) Radlk. (Agua) & av & 424 & 23 & $1,6^{\mathrm{a}}$ & 0,0 & 0,0 & 0,0 \\
\hline Annona neosalicifolia H.Rainer (Aneo) & a & 30 & 38 & 0,4 & 16,7 & 0,20 & 1,2 \\
\hline A. rugulosa (Schltdl.) H.Rainer (Arug) & a & 242 & 0 & 0,8 & 0,0 & 0,0 & 0,0 \\
\hline Apuleia leiocarpa (Vogel) J.F.Macbr. (Alei) & a & 61 & 8 & 0,4 & 10,6 & 0,85 & $1,7^{\mathrm{a}}$ \\
\hline Balfourodendron riedelianum (Engl.) Engl. (Brie) & a & 0,0 & 8 & 0,1 & 18,9 & 0,25 & 1,5 \\
\hline Banara tomentosa Clos (Btom) & a & 242 & 8 & 0,9 & 15,2 & 0,17 & 1,1 \\
\hline Cabralea canjerana (Vell.) Mart. (Ccan) & $\mathrm{a}$ & 121 & 0 & 0,4 & 16,7 & 0,67 & 1,5 \\
\hline Campomanesia xanthocarpa (Mart.) O.Berg (Cxan) & a & 61 & 38 & 0,6 & 13,6 & 0,29 & 1,3 \\
\hline Casearia sylvestris Sw. (Csyl) & a & 152 & 53 & $1,2^{\mathrm{a}}$ & 56,8 & 0,54 & $2,9^{\mathrm{a}}$ \\
\hline Cedrela fissilis Vell. (Cfis) & a & 0 & 0 & 0,0 & 7,6 & 0,32 & 0,9 \\
\hline Cestrum strigilatum Ruiz \& Pav. (Cstr) & ar & 364 & 30 & $1,4^{\mathrm{a}}$ & 0,0 & 0,0 & 0,0 \\
\hline Chrysophyllum gonocarpum (Mart. \& Eichler ex Miq.) Engl. (Cgon) & a & 61 & 0,0 & 0,3 & 16,7 & 0,33 & 1,4 \\
\hline C. marginatum (Hook. \& Arn.) Radlk. (Cmar) & a & 30 & 8 & 0,3 & 9,8 & 0,24 & 1,0 \\
\hline Cordia americana (L.) Gottschling \& J.S.Mill. (Came) & a & 0,0 & 38 & 0,7 & 47,7 & 1,21 & $3,4^{\mathrm{a}}$ \\
\hline C. trichotoma (Vell.) Arráb. ex Steud. (Ctri) & a & 242 & 30 & $1,3^{\mathrm{a}}$ & 18,2 & 0,68 & $1,6^{\mathrm{a}}$ \\
\hline Cupania vernalis Cambess. (Cver) & a & 2364 & 371 & $9,4^{\mathrm{a}}$ & 89,4 & 1,24 & $4,6^{\mathrm{a}}$ \\
\hline Diospyros inconstans Jacq. (Dinc) & a & 212 & 23 & 1,1 & 40,9 & 0,42 & $2,4^{\mathrm{a}}$ \\
\hline Eugenia rostrifolia D.Legrand (Eros) & a & 182 & 30 & 1,1 & 15,9 & 0,52 & 1,3 \\
\hline Ficus luschnathiana (Miq.) Miq. (Flus) & a & 30 & 0,0 & 0,2 & 25,8 & 0,81 & $2,0^{\mathrm{a}}$ \\
\hline Gymnanthes klotzschiana Müll.Arg. (Gklo) & a & 61 & 15 & 0,5 & 23,5 & 0,24 & 1,2 \\
\hline Inga marginata Willd. (Imar) & a & 636 & 53 & $2,2^{\mathrm{a}}$ & 4,5 & 0,06 & 0,4 \\
\hline Justicia sp. (Just) & ar & 333 & 0,0 & $1,3^{\mathrm{a}}$ & 0,0 & 0,0 & 0,0 \\
\hline Lonchocarpus cf. nitidus (Vogel) Benth. (Lnit) & a & 30 & 61 & 0,9 & 57,6 & 1,05 & $3,1^{\mathrm{a}}$ \\
\hline Machaerium paraguariense Hassl. (Mpar) & a & 30 & 106 & 1,1 & 34,8 & 0,59 & $2,4^{\mathrm{a}}$ \\
\hline Matayba elaeagnoides Radlk. (Mela) & a & 61 & 0,0 & 0,2 & 15,9 & 0,33 & 1,3 \\
\hline Myrcianthes pungens (O.Berg) D.Legrand (Mpun) & a & 91 & 15 & 0,6 & 12,1 & 0,11 & 0,8 \\
\hline Myrocarpus frondosus Allemão (Mfro) & a & 242 & 8 & 1,1 & 6,8 & 0,28 & 0,9 \\
\hline Myrsine umbellata Mart. (Mumb) & a & 182 & 30 & 0,9 & 22,7 & 0,36 & 1,5 \\
\hline Nectandra megapotamica (Spreng.) Mez (Nmeg) & a & 879 & 30 & $3,3^{\mathrm{a}}$ & 65,2 & 3,80 & $7,1^{\mathrm{a}}$ \\
\hline Ocotea puberula (Rich.) Nees (Opub) & a & 121 & 0,0 & 0,6 & 24,2 & 0,80 & $1,9^{\mathrm{a}}$ \\
\hline Parapiptadenia rigida (Benth.) Brenan (Prig) & a & 1152 & 30 & $3,5^{\mathrm{a}}$ & 43,9 & 1,44 & $3,7^{\mathrm{a}}$ \\
\hline Phytolacca dioica L. (Pdio) & a & 91 & 0,0 & 0,5 & 8,3 & 2,31 & $3,2^{\mathrm{a}}$ \\
\hline Picrasma crenata (Vell.) Engl. (Pcre) & a & 30 & 0 & 0,2 & 12,1 & 0,15 & 1,0 \\
\hline Piper aduncum L. (Padu) & ar & 1152 & 83 & $3,8^{\mathrm{a}}$ & 0,0 & 0,0 & 0,0 \\
\hline P. amalago L. (Pama) & ar & 182 & 8 & 1,1 & 0,0 & 0,0 & 0,0 \\
\hline Pombalia bigibbosa (A.St.Hil.) Paula-Souza (Pbig) & ar & 758 & 30 & $2,7^{\mathrm{a}}$ & 1,5 & 0,01 & 0,2 \\
\hline Prunus myrtifolia (L.) Urb. (Pmyr) & a & 121 & 45 & 0,7 & 15,2 & 0,45 & 1,4 \\
\hline Psychotria leiocarpa Cham. \& Schltdl. (Plei) & ar & 1394 & 15 & $4,5^{\mathrm{a}}$ & 0,0 & 0,0 & 0,0 \\
\hline Randia ferox (Cham. \& Schltdl.) DC. (Rfer) & av & 0 & 0 & 0,0 & 9,8 & 0,06 & 0,8 \\
\hline Ruprechtia laxiflora Meisn. (Rlax) & $\mathrm{a}$ & 30 & 23 & 0,5 & 23,5 & 0,42 & 1,5 \\
\hline Sebastiania brasiliensis Spreng. (Sebr) & a & 424 & 144 & $2,5^{\mathrm{a}}$ & 95,5 & 0,81 & $3,8^{\mathrm{a}}$ \\
\hline Sorocea bonplandii (Baill.) W.C.Burger et al. (Sbon) & av & 242 & 250 & $3,2^{\mathrm{a}}$ & 84,8 & 0,42 & $3,1 \mathrm{a}$ \\
\hline Strychnos brasiliensis Mart. (Stbr) & $\mathrm{a}$ & 121 & 83 & $1,4^{\mathrm{a}}$ & 3,8 & 0,01 & 0,2 \\
\hline Syagrus romanzoffiana (Cham.) Glassman (Srom) & a & 636 & 0,0 & $1,9^{\mathrm{a}}$ & 25,0 & 0,60 & $2,2^{\mathrm{a}}$ \\
\hline Tecoma stans (L.) Juss. ex Kunth (Tsta) & av & 0 & 8 & 0,1 & 18,2 & 0,26 & 1,0 \\
\hline Trichilia clausseni C.DC. (Tcla) & a & 1576 & 227 & $7,0 \mathrm{a}$ & 174,2 & 2,33 & $7,5^{\mathrm{a}}$ \\
\hline T. elegans A. Juss. (Tele) & av & 2545 & 523 & $10,7^{\mathrm{a}}$ & 49,2 & 0,18 & $2,2^{\mathrm{a}}$ \\
\hline Urera baccifera (L.) Gaudich. ex Wedd. (Ubac) & av & 0 & 8 & 0,1 & 7,6 & 0,06 & 0,6 \\
\hline Outras espécies - RN (CII: 26; CI: 13) & - & 1759 & 219 & 10,0 & - & - & - \\
\hline Outras espécies - estrato arbóreo (33) & - & - & - & - & 105,6 & 1,62 & 9,2 \\
\hline Somatório & - & 22485 & 3144 & 100 & 1535 & 29,63 & 100 \\
\hline
\end{tabular}


Cupania vernalis $(89,4)$ e Sorocea bonplandii (Baill.) W.C.Burger et al. $(84,8)$, que apresentaram elevada densidade de indivíduos, são, segundo Backes \& Irgang (2004), dispersadas por animais (zoocoria). Esta estratégia de dispersão pode ser um fator que influenciou a elevada densidade das espécies, quando estas aportam sementes em sítios com condições ecológicas favoráveis. Portanto, evidencia-se a importância de dispersores zoocóricos na manutenção da estrutura das comunidades avaliadas, visto que, segundo Barbosa et al. (2012), a dispersão de sementes pode causar um profundo efeito sobre a dinâmica, estrutura e composição de comunidades florestais.

As variações estruturais entre remanescentes florestais são mais discrepantes quando comparadas a áreas espacialmente distantes, devido possivelmente às discrepâncias ecológicas e à matriz vegetacional onde se localizam as florestas pesquisadas, salientado pela comparação do presente estudo com as pesquisas de Kunz et al. (2014) e Giácomo et al. (2015). As diferenças estruturais dentro de um mesmo remanescente florestal podem ser menores do que na comparação entre florestas de diferentes regiões fitoecológicas. Este caso engloba o presente estudo e a área pesquisada por Marcuzzo et al. (2013), em que diferentes espécies tiveram os maiores VIR, apesar de ambas terem sido realizadas no PEQC. A diferença estrutural entre os componentes arbóreos da presente pesquisa e da realizada por Marcuzzo et al. (2013), possivelmente, está relacionada com a maior área amostrada no presente estudo, à maior heterogeneidade ambiental, que incluiu diferentes posições topográficas, exposições do relevo (norte, oeste e sul), bem como diferentes estádios de regeneração (inicial, médio e avançado), características observadas in loco durante os deslocamentos.

$\mathrm{O}$ estrato regenerante teve as seguintes espécies com maior valor de Regeneração Natural Relativa (RNR): Trichilia elegans $(\mathrm{RNR}=10,7 \%)$, Cupania vernalis $(9,4 \%)$, Actinostemon concolor (Spreng.) Müll.Arg. (8,7\%), Trichilia clausseni (7,0\%), Psychotria leiocarpa Cham. \& Schltdl. (4,5\%), Piper aduncum L. (3,8\%), Parapiptadenia rigida (3,5\%), Nectandra megapotamica (3,3\%), Sorocea bonplandii (3,2\%) e Pombalia bigibbosa (A.St.Hil.) PaulaSouza (2,7\%). Algumas dessas espécies (T. elegans, $C$. vernalis, A. concolor, T. clausseni, N. megapotamica e $S$. bonplandii) são comuns na regeneração natural da FED, característica evidenciada por Meyer et al. (2012) no Estado de Santa Catarina, bem como constam entre as principais espécies do sub-bosque dessa tipologia florestal (Santos et al. 2012, Scipioni et al. 2009, Meyer et al. 2012). Constatou-se que arvoretas tolerantes à sombra (ex.: S. bonplandii e T. elegans) e arbustos demandantes de luz (ex.: P. aduncum e P. bigibbosa), espécies de porte pequeno, mas com diferentes exigências de luminosidade, se adaptaram ao estrato inferior da floresta. Este fato indica que existiam tanto ambientes mais sombreados, favoráveis às espécies tolerantes à sombra, quanto ambientes de maior luminosidade, condição ecológica essencial ao crescimento de espécies exigentes de luz.
As espécies Trichilia clausseni $(\mathrm{VIR}=7,5 \%$; $\mathrm{RNR}=$ $7,0 \%)$ e Parapiptadenia rigida $(\mathrm{VIR}=3,7 \%$; $\mathrm{RNR}=$ $3,5 \%$ ) tiveram elevada porcentagem de importância no estrato arbóreo (VIR) e proporção similar no estádio de regeneração natural (RNR). Por outro lado, Nectandra megapotamica teve queda brusca na porcentagem de importância (VIR=7,1\%; RNR=3,3\%), mas se manteve entre as principais espécies regenerantes, o que não foi observado para as espécies Allophylus edulis (VIR= $5,9 \% ; \mathrm{RNR}=2,0 \%)$ e Cordia americana $(\mathrm{VIR}=3,4 \%$; $\mathrm{RNR}=0,7 \%)$. Em contraste às demais espécies com maior VIR no estrato arbóreo, Cupania vernalis foi a única que teve um aumento em sua porcentagem de importância (VIR $=4,6 \%$; RNR $=9,4 \%$ ). Tais resultados expõem que algumas das principais espécies no estrato arbóreo mantêm o mesmo padrão no estrato regenerante. No caso de Cupania vernalis notou-se uma expressiva regeneração natural, o que pode ser atribuído à ausência de fatores limitantes e à facilidade de dispersão de sementes, uma vez que foi considerada, por Saueressig (2014), uma espécie zoocórica. Ressalta-se que alguns atributos como a elevada riqueza de espécies, a densidade de indivíduos, a variedade de hábitos e grupos ecológicos, bem como a presença de espécies de hábito arbóreo com expressiva RNR no estrato regenerante indicam a importância desse componente para o ecossistema. Tal afirmação é corroborada por Newbery et al. (2011), para os quais a regeneração natural é um mecanismo de recuperação e fornece estabilidade a médio prazo ao ecossistema florestal.

A análise de correspondência canônica (CCA) evidenciou quais variáveis ambientais se correlacionaram com a distribuição das espécies no componente arbóreo e na regeneração natural (Tab. 2). Para o componente arbóreo, os autovalores (autov.) gerados foram 0,198 (eixo 1) e 0,134 (eixo 2) e a variância (var.) total explicada foi $18 \%$ (eixo $1=10,7 \%$ e eixo $2=7,3 \%$ ). As variâncias explicadas podem ser consideradas baixas, visto que $18 \%$ da variância total da abundância das espécies foi explicada pelas cinco variáveis ambientais consideradas na CCA. No entanto, isso não compromete os resultados, já que, segundo Valentin (2012), houve alta correlação entre a ordenação das amostras baseada nas espécies e ordenação baseada nas variáveis ambientais no eixo $1(0,822)$ e no eixo $2(0,886)$. Em ecossistemas naturais, outras variáveis não consideradas nesse estudo têm influência na ocorrência de espécies, como fatores antrópicos e micro-organismos.

Para o estrato arbóreo, o primeiro eixo foi mais correlacionado com a profundidade do solo e a pedregosidade, enquanto o segundo eixo foi mais correlacionado, em ordem decrescente, com a exposição do relevo, teor de $\mathrm{MO}$ e abertura do dossel. O mapa de ordenação do estrato arbóreo (Fig. 3) indicou que apesar de determinadas espécies correlacionarem-se com algumas variáveis ambientais, outras como Apuleia leiocarpa (Vogel) J.F.Macbr., Campomanesia xanthocarpa (Mart.) O.Berg e Parapiptadenia rigida, ocorreram de maneira generalizada no gradiente ambiental, sem correlação por 
Tabela 2. Coeficientes de correlação entre as variáveis ambientais e os eixos de ordenação para espécies do componente arbóreo e da regeneração natural de um trecho de Floresta Estacional, na região central do Rio Grande do Sul.

\begin{tabular}{|c|c|c|c|c|c|c|}
\hline \multirow{4}{*}{ Variáveis ambientais } & \multicolumn{3}{|c|}{ Componente arbóreo } & \multicolumn{3}{|c|}{ Regeneração natural } \\
\hline & \multicolumn{3}{|c|}{ Classe I } & \multicolumn{3}{|c|}{ Classe II } \\
\hline & \multicolumn{6}{|c|}{ Correlação } \\
\hline & Eixo 1 & Eixo 2 & Eixo 1 & Eixo 2 & Eixo 1 & Eixo 2 \\
\hline Área basal & $*$ & - & $-0,606$ & $-0,205$ & 0,625 & 0,117 \\
\hline Abertura do dossel & 0,367 & $-0,383$ & - & - & $-0,471$ & 0,275 \\
\hline Exposição & $-0,068$ & $-0,740$ & - & - & - & - \\
\hline Profundidade & 0,584 & $-0,029$ & 0,530 & $-0,002$ & - & - \\
\hline Pedregosidade & $-0,505$ & $-0,115$ & - & - & - & - \\
\hline Serapilheira & - & - & $-0,352$ & 0,479 & $-0,026$ & 0,704 \\
\hline Argila & - & - & $-0,249$ & 0,406 & - & - \\
\hline Potássio & - & - & - & - & 0,129 & 0,512 \\
\hline Matéria orgânica & $-0,430$ & $-0,637$ & - & - & $-0,159$ & 0,392 \\
\hline
\end{tabular}

Classe I: $1 \leq \mathrm{DAP}<5 \mathrm{~cm}$; Classe II: H $\geq 20 \mathrm{~cm}$ e DAP $<1 \mathrm{~cm}$; *: variável não utilizada na confecção do mapa perceptual.

determinada variável ambiental analisada. Conforme Rodrigues et al. (2007), cada espécie tem um intervalo de tolerância em relação às variáveis ambientais. Isto indica que as variáveis ambientais analisadas não apresentaram extremos que limitassem o estabelecimento das populações arbóreas das três espécies supracitadas.

Percebe-se que as espécies Eugenia rostrifolia D.Legrand, Ficus luschnathiana (Miq.) Miq., Chrysophyllum gonocarpum (Mart. \& Eichler ex Miq.) Engl., Ruprechtia laxiflora Meisn. e Sebastiania brasiliensis, entre outras, mostraram-se positivamente localizadas em relação à matéria orgânica (MO) no solo, evidenciando que na floresta pesquisada essas espécies têm preferência por solos com maior teor de MO. A relação entre a distribuição de espécies e a matéria orgânica no solo tem sido observada em outras florestas (Marcon et al. 2014, Oliveira et al. 2015). O acúmulo de matéria orgânica no solo até níveis capazes de sustentar um fornecimento confiável de nutrientes e água para a biota é fundamental no desenvolvimento dos ecossistemas (Bechtold \& Naiman 2009, Terra et al. 2015), indicando que as espécies mencionadas acima são mais exigentes em termos de fertilidade do solo.

A exposição do relevo foi relacionada positivamente com a abundância de várias espécies, por exemplo, Cordia americana, Balfourodendron riedelianum (Engl.) Engl. e Gymnanthes klotzschiana Müll.Arg., indicando a maior abundância destas espécies nas faces do morro mais expostas à luminosidade solar. Observou-se um grupo de espécies com preferência por solos com maior teor de MO, onde se inclui Trichilia elegans, evidenciando certa exigência quanto às propriedades químicas do solo. A preferência de T. elegans, uma arvoreta de sub-bosque, por solos mais férteis também foi observada por AlmeidaScabbia et al. (2011). Por outro lado, Jones et al. (2016) propuseram que pode haver uma tendência geral das espécies de sub-bosque (herbáceas e arbustos/arvoretas) preferirem microsítios de menor altitude e mais úmidos. Todavia, as inferências de Jones et al. (2016) não se aplicam às espécies de sub-bosque amostradas no presente estudo, uma vez que foram abundantes em áreas declivosas e pedregosas, onde os solos menos profundos tendem a reter menos água.

A profundidade do solo foi outro fator ecológico condicionante do componente arbóreo, favorecendo a maior abundância de espécies como Ocotea puberula (Rich.) Nees e Cupania vernalis. De acordo com Lorenzi (1998), C. vernalis pode ser encontrada tanto na floresta madura quanto nos diferentes estádios da floresta secundária. Este aspecto é coerente com a população arbórea de $C$. vernalis que apresentou os maiores valores fitossociológicos na floresta do PEQC (DA= 89,4 indivíduos/ha; $1,24 \mathrm{~m}^{2} / \mathrm{ha}$; $\mathrm{VIR}=4,6 \%$ ), onde existem diferentes estádios sucessionais,

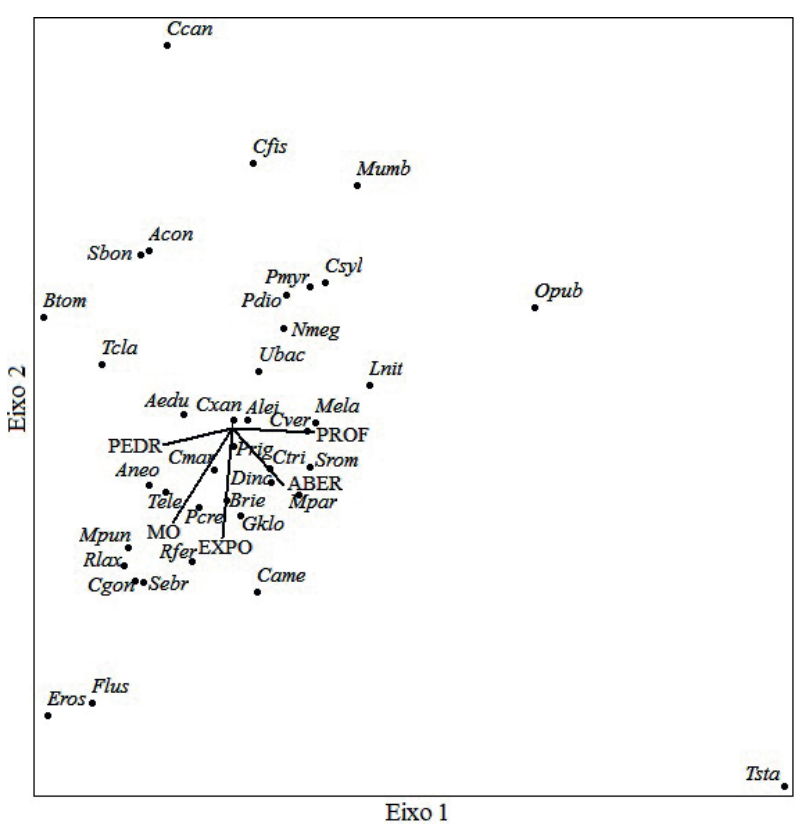

Fig. 3. Diagrama de ordenação gerado pela CCA a partir da abundância das espécies no estrato arbóreo e das variáveis ambientais de um trecho de Floresta Estacional, na região central do Rio Grande do Sul. Agudo, $\mathrm{RS}, 2013 . \mathrm{ABER}=$ abertura do dossel; $\mathrm{EXPO}=$ exposição do relevo; $\mathrm{MO}=$ matéria orgânica; $\mathrm{PEDR}=$ pedregosidade superficial; $\mathrm{PROF}=$ profundidade do solo. 
decorrentes em geral de distúrbios antrópicos. No caso de $O$. puberula ficou evidente que a espécie se desenvolveu melhor em substratos mais profundos. Contudo, a maior abundância de $O$. puberula nesses locais também se deve à influência antrópica, com a notória presença de clareiras ou estrada abandonada próxima ao local de ocorrência da espécie.

A maior abertura do dossel foi um fator favorável à abundância de certas espécies (ex.: Cordia trichotoma e Diospyros inconstans Jacq.), enquanto outras espécies tiveram maior abundância em comunidades com dossel mais fechado (ex.: Sorocea bonplandii e Trichilia clausseni). Ressalta-se que a maior abertura do dossel atribuiria ao sítio maior luminosidade no sub-bosque, ao passo que a menor abertura do dossel concede menor luminosidade, uma condição coerente com as características sucessionais das espécies Actinostemon concolor, Banara tomentosa Clos, S. bonplandii e T. clausseni, consideradas tolerantes à sombra (Grings \& Brack 2009, Scipioni et al. 2013) e comuns em estádios tardios de sucessão. Contudo, essa inferência deve ser considerada com cautela ao se analisar populações no componente arbóreo, uma vez que a altura do densiômetro para a medição da abertura do dossel fica a $1 \mathrm{~m}$ do solo.

Por meio de observações in loco, verificou-se que as espécies exóticas no estágio adulto (Tecoma stans (L.) Juss. ex Kunth e Psidium guajava L) ocorreram em parcelas que englobaram a floresta em estádio inicial e a bordadura, sendo tal condição corroborada pela posição positiva de T. stans em relação à abertura do dossel (Fig. $3)$. No trecho florestal amostrado, as maiores clareiras resultaram nitidamente do abandono de áreas cultivadas, indicando a relação da interferência humana com presença de árvores exóticas adultas na Unidade de Conservação. Além das clareiras de origem humana, a queda de árvores, conforme sugerido por Tabarelli \& Mantovani (1997), é um fator possivelmente condicionante da estrutura de espécies pioneiras nativas no estrato arbóreo. Isto foi evidenciado pela ocorrência de Boehmeria caudata Sw., Celtis iguanaea (Jacq.) Sarg., Manihot grahamii Hook. e Trema micrantha (L.) Blume apenas em parcelas com clareiras de origem humana, enquanto Urera baccifera (L.) Gaudich.) ocorreu nas duas condições. O hábito destas espécies, que são arvoretas ou árvores pequenas, evidencia que seus indivíduos não haviam sido suprimidos pelas árvores maiores. As informações supracitadas estão de acordo com Gudiel et al. (2016), os quais verificaram a relação positiva entre as maiores densidades de plantas não-nativas (arbustos e árvores analisadas) e a maior degradação e perturbação do habitat num todo. Estes autores também observaram que estradas e trilhas podem beneficiar árvores exóticas, devido possivelmente à abertura de nichos adjacentes e ao transporte intencional ou não de propágulos pelos humanos.

Em relação à regeneração natural, na CCA foram obtidos autovalores e variância total diferentes do estrato arbóreo (Classe I: eixo 1: autov. $=0,381$ e var. $=16,0 \%$; eixo 2: autov. $=0,180$ e var. $=7,5 \%$; Classe II: eixo 1: autov. $=0,219$ e var. $=10,0 \%$; eixo 2 : autov. $=0,142$ e var. $=6,4 \%$ ). As correlações entre a ordenação das amostras baseada nas espécies e ordenação baseada nas variáveis ambientais foram elevadas (Classe I: eixo $1=0,746$; eixo $2=0,648$; Classe II: eixo $1=$ $0,723$; eixo $2=0,773)$. No geral, a regeneração natural teve a distribuição influenciada por características do dossel, profundidade do solo, espessura da serapilheira acumulada, fatores físicos e químicos do solo. Conforme Sanaphre-Villanueva et al. (2016), assembleias de árvores juvenis são fortemente afetadas por condições bióticas e abióticas ao longo de gradientes sucessionais e topográficos. Tal afirmação corrobora com os resultados da presente pesquisa, em que se constatou a área basal, considerada um fator biótico de competição, e a espessura da serapilheira, um dos fatores abióticos, como determinantes da distribuição das duas classes regenerantes.

Para a regeneração natural da Classe I $(1 \leq \mathrm{DAP}<5$ $\mathrm{cm}$ ), observou-se que o eixo 1 dividiu as espécies quanto à profundidade do solo e à área basal, enquanto o eixo 2 evidenciou as espécies mais abundantes em solos com maior de teor de argila e áreas com camada de serapilheira mais espessa (Fig. 4A). No diagrama de ordenação da Classe II $(\mathrm{H} \geq 20 \mathrm{~cm}$ e DAP $<1 \mathrm{~cm})$, o eixo 1 separou as espécies com maior abundância em áreas mais abertas das espécies abundantes em comunidades com maior área basal e dossel mais fechado. Já o eixo 2 indicou que as espécies da porção superior do diagrama têm maior abundância em áreas com serapilheira mais espessa e valores mais elevados de K e MO (Fig. 4B). Nota-se que a área basal, a abertura do dossel, a espessura da serapilheira acumulada e alguns atributos edáficos (teor de argila, K e teor de MO) condicionaram a vegetação regenerante no trecho de floresta pesquisado. Conforme Calgaro et al. (2015), os atributos químicos do solo, associados ao nível de antropização, podem influenciar a ocorrência natural e o desenvolvimento de espécies. Além disso, Barroso et al. (2011) ressaltaram que as interações interespecíficas e a história da área podem influenciar a ocorrência de espécies mais que os fatores biofísicos, após constatarem a baixa correlação entre as espécies e os fatores abióticos avaliados. Dessa forma, fica evidente que os fatores abióticos, a autoecologia das espécies e a interferência antrópica podem impactar positiva ou negativamente a regeneração natural de espécies arbóreas em florestas com histórico de perturbação, como é o caso da área do PEQC.

Considerando a regeneração Classe I, constatou-se que as espécies tolerantes à sombra e com hábito de arvoreta (Actinostemon concolor e Sorocea bonplandii) foram mais abundantes em solos com maior área basal e menor profundidade. Este padrão contrastou com outro grupo de espécies nitidamente abundantes em comunidades com menor área basal e localizadas em solos mais profundos (ex.: Cupania vernalis e Strychnos brasiliensis Mart.). A correlação positiva das espécies $A$. concolor e $S$. bonplandii 


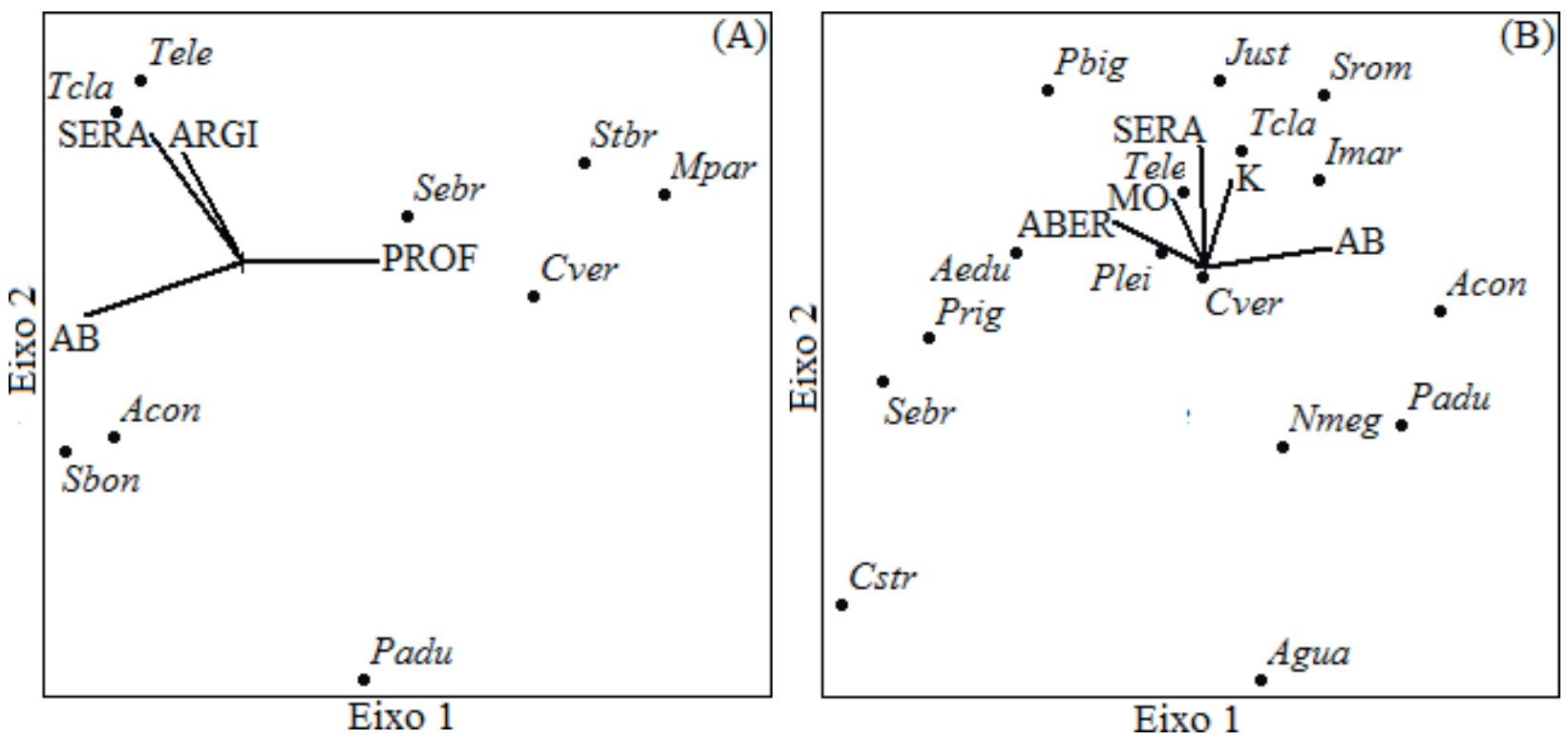

Fig. 4. Diagrama de ordenação gerados pela CCA a partir da abundância das espécies na regeneração natural Classe I (A) e Classe II (B) e das variáveis ambientais, de um trecho de Floresta Estacional Decidual no Rebordo do Planalto Meridional. Agudo, RS, 2014. AB = área basal; ABER = abertura do dossel; $\mathrm{ARGI}=$ argila; $\mathrm{K}=$ potássio; $\mathrm{MO}=$ matéria orgânica; $\mathrm{PROF}=$ profundidade do solo; $\mathrm{SERA}=$ serapilheira.

com a área basal evidencia as características sucessionais das espécies supracitadas, consideradas tolerantes à sombra ou secundárias tardias (Grings \& Brack 2009, Scipioni et al. 2013), as quais tendem a suportar ambientes com certa competição interespecífica.

As meliáceas Trichilia clausseni e Trichilia elegans foram positivamente relacionadas à espessura da serapilheira e ao teor de argila do solo, enquanto Piper aduncum foi teve posição negativa em relação a estas variáveis. Conforme Martins \& Rodrigues (1999), a maior quantidade de serapilheira sobre o solo pode interferir em fatores do microsítio (e.g. luz, temperatura e umidade do solo). Esta afirmação indica que a regeneração natural de certas espécies, por exemplo, na presente pesquisa das tolerantes ao sombreamento $T$. clausseni e $T$. elegans, pode ser mais sensível às variações extremas do microsítio, enquanto outras espécies, como $P$. aduncum, seriam mais resistentes às variações.

A ordenação da regeneração natural da Classe II (plantas de menor tamanho) evidenciou que as espécies da porção superior do mapa (ex.: Syagrus romanzoffiana (Cham.) Glassman e Trichilia clausseni) tiveram relação positiva com a serapilheira. Observa-se na CCA que os vetores da serapilheira e do $\mathrm{K}$ ficaram relativamente próximos, evidenciando que essas variáveis apresentaram certa correlação espacial. Tal fato pode estar relacionado à alta mobilidade deste nutriente, sendo translocado facilmente da serapilheira para o solo (Malavolta et al. 1997, Marcuzzo et al. 2013).

$\mathrm{Na}$ Classe II foi constatada a maior abundância de espécies em comunidades com maior abertura do dossel e menor área basal (ex.: Allophylus edulis e Parapiptadenia rigida), ao contrário de outras espécies como Actinostemon concolor e Inga marginata Willd. (posição negativa com a abertura do dossel e positiva com a área basal). Também foi notada a divisão de espécies em relação ao vetor de MO, havendo espécies mais abundantes em áreas com elevado teor de MO (ex.: Justicia sp. e Pombalia bigibbossa), enquanto outras espécies tiveram posição negativa em relação a esta variável (ex.: Allophylus guaraniticus (A. St.-Hil.) Radlk. e Nectandra megapotamica).

Notou-se que as espécies Actinostemon concolor, Cupania vernalis, Sebastiania brasiliensis, Trichilia clausseni e Trichilia elegans foram as populações presentes nas três classes de vegetação analisadas, sendo relacionadas com diferentes variáveis, conforme o estádio de desenvolvimento. Contudo, o componente arbóreo e a regeneração natural de menor tamanho $(H \geq 20 \mathrm{~cm}$ e DAP $<1 \mathrm{~cm}$ ) de $A$. concolor e T. elegans foram mais abundantes, respectivamente, em áreas com menor abertura do dossel e maior teor de matéria orgânica do solo.

De forma geral, constatou-se que características edáficas e aspectos do dossel têm maior influência na regeneração natural do que no estrato arbóreo. Isso pode ser explicado pela maior dependência que os indivíduos jovens, em fase de estabelecimento, apresentam em relação as condições abióticas, quando comparados a indivíduos do estrato arbóreo. Indivíduos estabelecidos e presentes na floresta por longo tempo, certamente foram influenciados por maior número de variáveis abióticas e bióticas. Nesse sentido, talvez a identificação da influência de variáveis ambientais sobre as espécies, seja mais intuitiva, quando se utiliza as menores classes de tamanho na análise. Tal hipótese poderá ser melhor evidenciada mediante análise da dinâmica da regeneração natural em relação aos fatores anteriormente analisados, bem como outros fatores não considerados. 


\section{AGRADECIMENTOS}

À Coordenação de Aperfeiçoamento de Pessoal de Nível Superior, pela concessão da bolsa de Doutorado ao primeiro autor, durante a realização da pesquisa. Ao Fundo Socioambiental da Caixa Econômica Federal, por meio do projeto ( $\left.\mathrm{n}^{\circ} 015.007 / 2012\right)$, pelo auxílio financeiro para a realização da pesquisa. Às pessoas que auxiliaram na coleta de dados: Adriana M. Griebeler, Álvaro L. P. Berghetti, Aquiles B. Naressi, Caira Tolfo, Camila M. Ribeiro, Felipe M. Barbosa, Jairo L. Z. Peripolli, Jessé C. Mezzomo, Lisandro Bolzan, Luiz Rodrigues, Manoel B. P. Matos, Matheus R. da Silva e Thairini Zavistanovicz.

\section{REFERÊNCIAS}

Almeida-Scabbia, R.J., Schlittler, F.H.M., César, O., Monteiro, R., Gomes, E.P.C. \& Romaniuc Neto, S. 2011. Características físico-químicas do solo e distribuição de espécies arbóreas em um trecho de cuesta basáltica, Analândia, SP, Brasil. Revista Brasileira de Biociências 9(3):322-331.

Alvares, C.A., Stape, J.L., Sentelhas, P.C., Gonçalves, J.L.de M. \& Sparovek, G. 2013. Köppen's climate classification map for Brazil. Meteorologische Zeitschrift 22(6):711-728.

Backes, P. \& Irgang, B. 2004. Mata Atlântica: as árvores e a paisagem. Paisagens do Sul, Porto Alegre. 396 p.

Baker, T.R., Diaz, D.M.V., Moscoso, V.C., Navarro, G., Monteagudo, A., Pinto, R., Cangani, K., Fyllas, N.M., Gonzalez, G.L., Laurance, W.F., Lewis, S.L., Lloyd, J., Steege, H.ter, Terborgh, J.W. \& Phillips, O.L. 2016. Consistent, small effects of treefall disturbances on the composition and diversity of four Amazonian forests. Journal of Ecology 104(2):497-506.

Barbosa, J.M., Eisenlohr, P.V., Rodrigues, M.A. \& Barbosa, K.V. 2012. Ecologia da dispersão de sementes em florestas tropicais. In Ecologia de florestas tropicais do Brasil (S.V. Martins ed.). Editora Universidade Federal de Viçosa, Viçosa, p. 85-106.

Barroso, J.G., Salimon, C.I., Silveira, M. \& Morato, E.F. 2011. Influência de fatores ambientais sobre a ocorrência e distribuição espacial de cinco espécies madeireiras exploradas no Estado do Acre, Brasil. Scientia Forestalis 39(4):489-499.

Bechtold, J.S. \& Naiman, R.J. 2009. A quantitative model of soil organic matter accumulation during floodplain primary succession. Ecosystems 12(8):1352-1368.

Brack, P., Rodrigues, R.S., Sobral, M. \& Leite, S.L.C. 1998. Árvores e arbustos na vegetação natural de Porto Alegre, Rio Grande do Rio Grande do Sul, Brasil. Iheringia. Série Botânica 51(2):139-166.

Byng, J.W., Chase, M.W., Christenhusz, M.J.M., Fay, M.F., Judd, W.S., Mabberley, D.J., Sennikov, A.N., Soltis, D.E., Soltis, P.S. \& Stevens, P.F. 2016. An update of the Angiosperm Phylogeny Group classification for the orders and families of flowering plants: APG IV. Botanical Journal of the Linnean Society 181(1):1-20.

Calgaro, H.F., Buzetti, S., Silva, L.R., Stefanini, L., Miranda, L.P.M., Moraes, M.A. \& Moraes, M.L.T. 2015. Distribuição natural de espécies arbóreas em áreas com diferentes níveis de antropização e relação com os atributos químicos do solo. Revista Árvore 39(2):233243.

Chai, S.L. \& Tanner, E.V.J. 2011. 150-year legacy of land use on tree species composition in old-secondary forests of Jamaica. Journal of Ecology 99(1):113-121.

Chazdon, R. 2012. Regeneração de florestas tropicais. Boletim do Museu Paraense Emílio Goeldi. Ciências Naturais 7(3):195-218.

Chazdon, R.L., Letcher, S.G., Breugel, M.van, Martínez-Ramos, M., Bongers, F. \& Finegan, B. 2007. Rates of change in tree communities of secondary Neotropical forests following major disturbances. Philosofical Transactions of the Royal Society B: Biological Sciences 362(2):273-289
Empresa Brasileira de Pesquisa Agropecuária. Centro Nacional de Pesquisa de Solos. 1997. Manual de métodos de análise de solo. EMBRAPA-CNPS, Rio de Janeiro. 212 p.

Felfili, J.M., Carvalho, F.A., Libano, V.F., Pereira, B.A.S. \& Machado, E.L.M. 2011. Análise multivariada: princípios e métodos em estudos de vegetação. In Fitossociologia no Brasil: métodos e estudos de casos (J.M. Felfili, P.V. Eisenlohr, M.M.R.F. Melo, L.A. Andrade \& J.A.A. Meira Neto, eds.). Editora Universidade Federal de Viçosa, Viçosa, p. 122-155.

Fortuny, X., Chauchard, S. \& Carcaillet, C. 2017. Confounding legacies of land uses and land-form pattern on the regional vegetation structure and diversity of Mediterranean montane forests. Forest Ecology and Management 384:268-278.

Ferreira Júnior, W.G., Schaefer, C.E.G.R. \& Silva, A.F. 2012. Uma visão pedogeomorfológica sobre as formações florestais da Mata Atlântica. In Ecologia de florestas tropicais do Brasil (Martins, S.V.). Editora Universidade Federal de Viçosa, Viçosa, p. 141-174.

Finol, H. 1971. Nuevos parâmetros a considerar-se en el análises estructural de las selvas virgenes tropicales. Revista Forestal Venezolana 14(21):24-42.

Forzza, R.C.; Leitman, P.M.; Costa, A.F.; Carvalho Jr., A.A.; Peixoto, A.L.; Walter, B.M.T.; Bicudo, C.; Zappi, D.; Costa, D.P.; Lleras, E.; Martinelli, G.; Lima, H.C.; Prado, J.; Stehmann, J.R.; Baumgratz, J.F.A.; Pirani, J.R.; Sylvestre, L.; Maia, L.C.; Lohmann, L.G.; Queiroz, L.P.; Silveira, M.; Coelho, M.N.; Mamede, M.C.; Bastos, M.N.C.; Morim, M.P.; Barbosa, M.R.; Menezes, M.; Hopkins, M.; Secco, R.; Cavalcanti, T.B. \& Souza, V.C. 2015. Lista de Espécies da Flora do Brasil. Jardim Botânico do Rio de Janeiro. Disponível em: http://www.floradobrasil.jbrj.gov.br. Acessado em 21.04. 2015.

Giácomo, R.G., Pereira, M.G., Carvalho, D.C., Medeiros, V.S. \& Gaui, T.D. 2015. Florística e fitossociologia em áreas de Cerradão e Mata Mesofítica na Estação Ecológica de Pirapitinga, MG. Floresta e Ambiente 22(3):287-298.

Giehl, E.L.H., Athayde, E.A., Budke, J.C., Gesing, J.P.A., Einsiger, S.M. \& Canto-Dorow, T.S. 2007. Espectro e distribuição vertical das estratégias de dispersão de diásporos do componente arbóreo em uma floresta estacional no sul do Brasil. Acta Botanica Brasilica 21(1):137-145.

Grings, M. \& Brack, P. 2009. Árvores na vegetação nativa de Nova Petrópolis, Rio Grande do Sul. Iheringia. Série Botânica 64(1):5-22.

Gudiel, A.A., Nieves, S.C., Reuter, K.E. \& Sewall, B.J. 2016. The effect of anthropogenic disturbance on non-native plant species in Madagascar. Journal of Tropical Ecology 32(6):543-554.

Instituto Brasileiro de Geografia e Estatística. 2012. Manual técnico da vegetação brasileira. IBGE, Rio de Janeiro. 275 p.

Jones, M.M., Ruokolainen, K., Martinez, N.C.L. \& Tuomisto, H. 2016. Differences in topographic and soil habitat specialization between trees and two understorey plant groups in a Costa Rican lowland rain forest. Journal of Tropical Ecology 32(6):482-497.

Jorge, L.A.B., Millani, T.M. Fonseca, R.C.B. \& Arruda, A.A. 2015. Estrutura diamétrica e arranjo espacial das espécies mais abundantes de um fragmento de Floresta Estacional Semidecidual em Botucatu, SP. Floresta e Ambiente 22(3):355-367.

Kunz, S.H., Moreau, J.S., Spadeto, C., Martins, S.V. Stefanello, D. \& Ivanauskas, N.M. 2014. Estrutura da comunidade arbórea de trecho de Floresta Estacional Sempre-Verde e similaridade florística na Região Nordeste do Mato Grosso, Brasil. Floresta e Ambiente 21(4):429-440.

Liebsch, D., Maçaneiro, J.P., Marcon, A.K. \& Galvão, F. 2016. Influência de impactos antrópicos em fragmentos de Floresta Ombrófila Mista em Santa Catarina. Pesquisa Florestal Brasileira 36(3):277-287.

Lorenzi, H. 1998. Árvores brasileiras. Instituto Plantarum, Nova Odessa, v.1. p. 316

Lucheta, F., Teixeira, M., Koch, N.M. \& Freitas, E.M. 2015. Estrutura da comunidade arbórea de um fragmento de floresta ribeirinha do rio Taquari, Lajeado, Rio Grande do Sul, Brasil. Iheringia. Série Botânica 70(2):343-355.

Malavolta, E., Vitti, G.C. \& Oliveira, S.A. 1997. Avaliação do estado nutricional das plantas: princípios e aplicações. Associação Brasileira da Potassa e do Fosfato, Piracicaba. 319 p.

Marchesini, V.A., Sala, O.E. \& Austin, A.T. 2009. Ecological consequences of a massive flowering event of bamboo (Chusquea culeou) in a 
temperate forest of Patagonia, Argentina. Journal of Vegetation Science 20(3):424-432.

Marchiori, J.N.C. 2013. Elementos de dendrologia. Editora Universidade Federal de Santa Maria, Santa Maria. 216 p.

Marcon, A.K., Silva, A.C., Higuchi, P., Ferreira, T.S., Missio, F.F., Salami, B., Dalla Rosa, A., Negrini, M., Bento, M.A. \& Buzzi Júnior, F. 2014. Variação florístico-estrutural em resposta à heterogeneidade ambiental em uma floresta nebular em Urubici, Planalto Catarinense. Scientia Forestalis 42(3):439-450.

Marcuzzo, S.B., Araujo, M.M. \& Longhi, S.J. 2013. Estrutura e relações ambientais de grupos florísticos em fragmento de Floresta Estacional Subtropical. Revista Árvore 37(2):275-287.

Martins, S.V. \& Rodrigues, R.R. 1999. Produção de serapilheira em clareiras de uma floresta estacional semidecidual no município de Campinas, SP. Revista Brasileira de Botânica 22(3):405-412.

Meyer, L., Gasper, A.L., Sevegnani, L., Schorn, L.A., Lingner, D.V., Vibrans, A.C., Verdi, M., Santos, A.S., Dreveck, S. \& Korte, A. 2012. Regeneração natural da Floresta Estacional Decidual em Santa Catarina. In Floresta Estacional Decidual (A.C. Vibrans, L. Sevegnani, A.L. Gasper \& D.V. Lingner, eds.). Edifurb, Blumenau, p. 167-187.

Newbery, D.M., Lingenfelder, M., Poltz, K.F., Ong, R.C. \& Ridsdale, C.E. 2011. Growth responses of understorey trees to drought perturbation in tropical rainforest in Borneo. Forest Ecology and Management 262(12):2095-2107.

Oliveira Filho, A.T., Carvalho, D.A., Fontes, M.A.L., Berg, E.V.D., Curi, N. \& Carvalho, W.A.C. 2004. Variações estruturais do compartimento arbóreo de uma Floresta Semidecídua Alto-Montana na Chapada das Perdizes, Carrancas, MG. Revista Brasileira de Botânica 27(2):291309.

Oliveira, M.L.A.A., Grings, M., Richter, F.S. \& Backes, A.R. 2015. Composição, estrutura e fatores edáficos condicionantes da distribuição das espécies do componente arbóreo em floresta ribeirinha do rio Ibirapuitã, Bioma Pampa. Iheringia. Série Botânica 70(2):245-263.

Oliveira, R.R., Zaú, A.S., Lima, D.F., Silva, M.B.R., Vianna, M.C. Sodré, D.O. \& Sampaio, P.D. 1995. Significado ecológico da orientação de encostas no maciço da Tijuca, Rio de Janeiro. Oecologia Brasiliensis 1(1):523-541.

Pedron, F.A. \& Dalmolin, R.S.D. 2011. Solos da região do rebordo do Planalto Meridional no Rio Grande do Sul. In A Floresta Estacional Subtropical: caracterização e ecologia no rebordo do Planalto Meridional (M.V. Schumacher, S.J. Longhi, E.J. Brun \& R.V. Kilca, eds.). Editora Pallotti, Santa Maria, p. 33-51.

Rio Grande do Sul. 2005. Cria o Parque Estadual Quarta Colônia e dá outras providências. Diário Oficial do Estado, Porto Alegre, RS. Decreto n. 44.186, de 19 de dezembro de 2005. Disponível em: http://www. al.rs.gov.br/legis/M010/M0100099.ASP?Hid_Tipo=TEXTO\&Hid_ TodasNormas $=49252 \&$ hTexto $=\&$ Hid_IDNorma $=49252$. Acessado em 27.10.2016.

Rodrigues, L.A., Carvalho, D.A., Oliveira Filho, A.T.de \& Curi, N. 2007. Efeitos de solos e topografia sobre a distribuição de espécies arbóreas em um fragmento de Floresta Estacional Semidecidual, em Luminárias, MG. Revista Árvore 31(1):25-35.

Sanaphre-Villanueva, L., Dupuy, J.M., Andrade, J.L., Reyes-García, C., Paz, H. \& Jackson, P.C. 2016. Functional diversity of small and large trees along secondary succession in a tropical dry forest. Forests 7(8):1-15.

Santos, R.D., Lemos, R.M.de, Santos, H.G.dos, Ker, J.C., Anjos, L.H.C. \& Shimizu, S.H. 2013. Manual de descrição e coleta de solo no campo. Sociedade Brasileira de Ciência do Solo, Viçosa. 100 p.

Santos, S.C., Budke, J.C. \& Muller, A. 2012. Regeneração de espécies arbóreas sob a influência de Merostachys multiramea Hack. (Poaceae) em uma floresta subtropical. Acta Botanica Brasilica 26(1):218-229.
Sassen, M. \& Sheil, D. 2013. Human impacts on forest structure and species richness on the edges of a protected mountain forest in Uganda. Forest Ecology and Management 307:206-218.

Saueressig, D. 2014. Plantas do Brasil: árvores nativas. Editora Plantas do Brasil, Irati. 432 p.

Sccoti, M.S.V. 2012. Dinâmica da vegetação em remanescente de Floresta Estacional Subtropical. Tese 177 f., Universidade Federal de Santa Maria, Santa Maria.

Schneider, G. \& Rocha, F.S. 2014. Levantamento florístico e fitossociológico do componente arbóreo de um fragmento de Floresta Estacional Decidual em São Miguel do Oeste, Santa Catarina. Biotemas 27(2):43-55.

Schorn, L.A., Meyer, L., Sevegnani, L., Vibrans, A.C., Lingner. D.V., Gasper, A.L., Uhlmann, A., Verdi, M. \& Stival-Santos, A. 2014. Fitossociologia de fragmentos de Floresta Estacional Decidual no Estado de Santa Catarina - Brasil. Ciência Florestal 24(4):821-831.

Scipioni, M.C., Longhi, S.J., Brandelero, C., Pedron, F.A. \& Reinert, D.J. 2012. Análise fitossociológica de um fragmento de Floresta Estacional em uma catena de solos no Morro do Cerrito, Santa Maria, RS. Ciência Florestal 22(3):457-466.

Scipioni, M.C., Longhi, S.J., Reinert, D.J., Araujo, M.M. \& Pedron, F.A. 2010. Distribuição do compartimento arbóreo em gradiente de relevo e solos na encosta Meridional da Serra Geral, RS. Ciência Rural 40(6):1295-1301.

Scipioni, M.C., Longhi, S.J., Araujo, M.M. \& Reinert, D.J. 2009. Regeneração natural de um fragmento da Floresta Estacional Decidual na Reserva Biológica do Ibicuí-Mirim (RS). Floresta 39(3):675-690.

Scipioni, M.C., Galvão, F. \& Longhi, S.J. 2013. Composição florística e estratégias de dispersão e regeneração de grupos florísticos em Florestas Estacionais Deciduais no Rio Grande do Sul. Floresta 43(2):241-254.

Scolari, G.O., Andrade, G.R., Dias, J., Moscogliato, A.V. \& Torezan, J.M.D. 2010. Riqueza e abundância de espécies lenhosas em reflorestamento de Pinus taeda L. e Floresta Ombrófila Mista no Centro - Leste do Estado do Paraná. Semina: Ciências Agrárias 31(1):1361-1366

Silva, W.C., Marangon, L.C., Ferreira, R.L.C., Feliciano, A.L.P., Aparício, P.S. \& Costa Junior, R. F. 2010. Estrutura horizontal e vertical do componente arbóreo em fase de regeneração natural na mata Santa Luzia, no município de Catende-PE. Revista Árvore 34(5):863-869.

Souza, A.L. \& Soares, C.P.B. 2013. Florestas nativas: estrutura, dinâmica e manejo. Editora Universidade Federal de Viçosa, Viçosa. 322 p.

Sühs, R.B. \& Budke, J.C. 2011. Spatial distribution, association patterns and richness of tree species in a seasonal forest from the Serra Geral formation, southern Brazil. Acta Botanica Brasilica 25(3):605-617.

Tabarelli, M. \& Mantovani, W. 1997. Colonização de clareiras naturais na floresta atlântica no sudeste do Brasil. Revista Brasileira de Botânica 20(1):57-66.

Tedesco, M.J., Volkweiss, S.J. \& Bohnen, H. 1995 Análises de solo, plantas e outros materiais. Universidade Federal do Rio Grande do Sul, Porto Alegre. $174 \mathrm{p}$.

Terra, M.C.N.S., Mello, J.M. \& Mello, C.R. 2015. Relação espacial do carbono da vegetação e matéria orgânica do solo na Serra da Mantiqueira. Floresta e Ambiente 22(4):446-455.

Valentin, J.L. 2012. Ecologia numérica: uma introdução à análise multivariada de dados ecológicos. Editora Interciência, Rio de Janeiro. $153 \mathrm{p}$.

Wrege, M.S., Steinmetz, S., Matzenauer, R., Radin, B., Almeida, I.R., Reisser Júnior, C., Maluf, J.R.T., Bueno, A.C., Pasinato, A., Cunha, G.R., Prestes, S.D., Dalmago, G.A., Pires, J.L.F., Santi, A., Berlato, M.A. \& Didoné, I.A. 2011. Atlas climático: Rio Grande do Sul. Fundação Estadual de Pesquisa Agropecuária /Centro Estadual de Meteorologia, Porto Alegre. $185 \mathrm{p}$. 